\title{
Mean arterial blood pressure and neonatal cerebral lesions
}

\author{
V M MIALl-ALLEN, L S DE VRIES, AND A G L WHITELAW \\ Department of Paediatrics and Neonatal Medicine, Royal Postgraduate Medical School, Hammersmith \\ Hospital, London
}

SUMMARY Computerised continuous measurement of mean arterial blood pressure (MAP) and serial cranial ultrasonography in 33 infants of $<31$ weeks' gestation showed that a MAP of $<30 \mathrm{~mm} \mathrm{Hg}$ for over an hour was significantly associated with severe haemorrhage, ischaemic cerebral lesions, or death within 48 hours. No severe lesions developed with a MAP $\geqslant 30 \mathrm{~mm} \mathrm{Hg}$.

Disturbances of blood pressure may be important in the pathogenesis of intracranial lesions in preterm infants. Periventricular haemorrhage and leucomalacia have been attributed to excessive and insufficient cerebral blood flow, respectively, ${ }^{1-3}$ and there is an association between hypotension and periventricular haemorrhage. ${ }^{45}$ Limitations of previous studies have included incomplete delineation of cerebral lesions, intermittent blood pressure measurements (missing short term variations), and failure to exclude infants with cerebral lesions at the start of recording. We overcame these problems by using computerised, continuous acquisition of data and serial high resolution cranial ultrasonography, and by excluding any infant with a lesion at the start of recording.

\section{Patients and methods}

Infants of $26-30$ weeks' gestation were eligible for the study, carried out from February 1985 to September 1986, provided they had an umbilical artery catheter in place by the time they were 6 hours old, a normal initial cranial ultrasound scan, and no evidence of congenital abnormality. Umbilical artery catheters incorporating an oxygen electrode and a side hole (Neocath, Biomedical Sensors Ltd, High Wycombe, UK) were advanced to the level of T8-T10 and infused through flushing devices (Intraflo, Sorensen Research, Utah, USA). Signals were relayed from a transducer (Medex MX800, Medex Inc, Haslingden, Rossendale, UK) to a neonatal monitor (Model 431A, Tektronix Ltd, Harpenden, Herts, UK) interfaced with an analog digital converter an an Apple IIe microcomputer. We chose this method in preference to intermittent recording, which misses short term fluctuations (figure). Arterial waveforms were collected over 20 second periods and the true mean arterial pressure (MAP) derived. Data were stored on floppy disk and the 20 second cycles repeated. Ultrasound scans were made at least daily during the first week and then weekly until discharge, with an ATL Mark III sector scanner with multifrequency head $(3 / 5 / 7 \cdot 5$ $\mathrm{MHz}$.

Thirty three infants were entered into the study; 28 were having mechanical ventilation, and five required headbox oxygen for the respiratory distress syndrome. Treatment was independent of the results of the study, the clinicians having no access to the data collected. Pethidine and pancuronium were given when required, and plasma or $5 \%$ human albumin was given slowly $(10-15 \mathrm{ml} / \mathrm{kg})$ if perfusion was considered inadequate. Seven infants received inotropic support for extreme underperfusion (dopamine or dobutamine, or both, in a dose of $5-10 \mu \mathrm{g} / \mathrm{kg} / \mathrm{min}$ ) starting on average $101 / 2$ hours after birth.

Statistical analysis of differences in proportions was done using the $\chi^{2}$ square test with Yates's correction.

\section{Results}

Data recording started an average of three hours

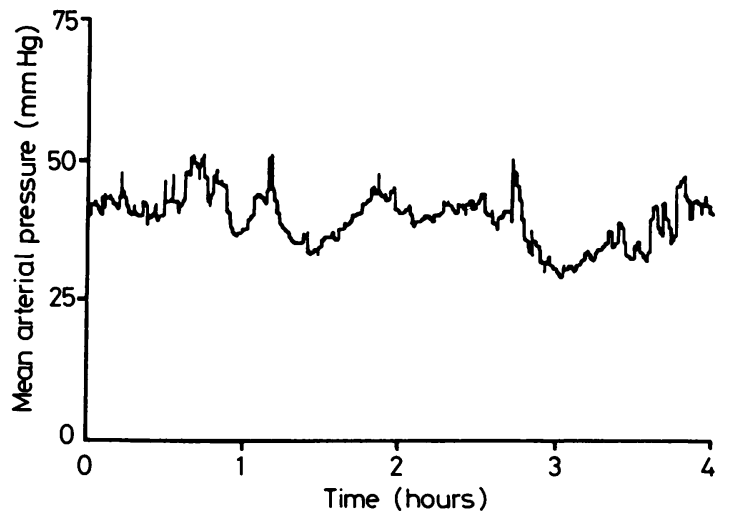

Figure Mean arterial pressure from an infant of birth weight $1000 \mathrm{~g}$ showing spontaneous short term fluctuations. 
after birth (range 2-5 hours) and continued for an average of 86 hours (range 30-348). Cranial ultrasound appeareances were classified by LSdeV, who did not know the MAP results, and the MAP results were analysed by VMA, who did not know the ultrasound classification.

Ultrasound appearances were classified as normal; showing mild changes (for example, germinal layer, small intraventricular haemorrhage, or transient periventricular densities of three to 12 days' duration); or showing persistent severe lesions (for example, extensive haemorrhage or periventricular leucomalacia). ${ }^{6}$ The latter group also included infants who died at less than 48 hours old as there may have been insufficient time for ischaemic changes to become visible.

MAP values were classified as follows: always $\geqslant 35 \mathrm{~mm} \mathrm{Hg} ; 30-34 \mathrm{~mm} \mathrm{Hg}$ for longer than one hour but never $<30 \mathrm{~mm} \mathrm{Hg} ; 25-29 \mathrm{~mm} \mathrm{Hg}$ for longer than one hour but never $<25 \mathrm{~mm} \mathrm{Hg}$; and $<25 \mathrm{~mm}$ $\mathrm{Hg}$ for longer than one hour. Values of $\leqslant 29 \mathrm{~mm} \mathrm{Hg}$ were found only in the first 24 hours, before cerebral lesions developed, and never occurred for the first time after 24 hours. In the two infants who died hypotension was not a terminal event, having been present for 22 hours. Increase in blood pressure variability was not seen when circulatory support was given.

The outcome was significantly worse the lower the MAP (table). None of the infants who maintained a MAP of $\geqslant 30 \mathrm{~mm} \mathrm{Hg}$ developed severe lesions. Infants with a MAP of $<30 \mathrm{~mm} \mathrm{Hg}$ had significantly more severe lesions and early deaths than those with

Table Grouping of infants by lowest mean arterial pressure and cranial ultrasound appearances

\begin{tabular}{|c|c|c|c|}
\hline \multirow{2}{*}{$\begin{array}{l}\text { Mean arterial } \\
\text { pressure }>1 \\
\text { hour }(\mathrm{mm} \mathrm{Hg})\end{array}$} & \multicolumn{3}{|c|}{ Cranial ultrasound appearances } \\
\hline & Normal & Transient & Severe \\
\hline$\geqslant 35$ & 5 & 1 & 0 \\
\hline $30-34$ & 0 & 6 & 0 \\
\hline $25-29$ & 0 & 6 & $\begin{array}{l}3 \text { IVH/bilateral } \\
\text { extension; } \\
\text { IVH/ } \\
\text { infarct/ } \\
\text { hydrocephalus; } \\
\text { IVH/PVL }\end{array}$ \\
\hline$<25$ & 1 & 5 & $\begin{array}{l}6 \text { IVH/early death; } \\
\text { IVH/early death; } \\
\text { IVH/extension; } \\
\text { IVH/extension; } \\
\text { IVH/extension/ } \\
\text { infarct; PVL }\end{array}$ \\
\hline
\end{tabular}

$\overline{I V H=\text { intraventricular haemorrhage; } \quad P V L=\text { periventricular }}$ haemorrhage. a MAP of $\geqslant 30 \mathrm{~mm} \mathrm{Hg}(\mathrm{p}<0 \cdot 01)$. The average weight of infants with an MAP of $\geqslant 30 \mathrm{~mm} \mathrm{Hg}$ was $1040 \mathrm{~g}$ (range 700-1700) and with an MAP of $<30$ $\mathrm{mm} \mathrm{Hg}$ it was $1060 \mathrm{~g}$ (range 700-1600). The average gestational age of those with an MAP of $\geqslant 30 \mathrm{~mm} \mathrm{Hg}$ was 27.8 weeks (range 26-30) and of those with an MAP of $<30 \mathrm{~mm} \mathrm{Hg} 27.7$ weeks (range 26-30). Thus the differences in MAP between the two groups were not due to differences in weight or maturity.

\section{Discussion}

Other studies have placed most emphasis on the instability of blood pressure or its transition from low to fairly high pressures ${ }^{3-5}$; in contrast, we have shown a significant association between sustained low mean arterial pressure and cerebral lesions or early death.

MAP was chosen in preference to systolic pressure alone because it is less subject to error from damping and is used to calculate cerebral perfusion pressure. Systolic pressure does not represent the whole of the cardiac cycle, whereas MAP does. Hypotension may relate to the underlying diseases or treatments, but whatever the cause intervention to maintain MAP needs further evaluation in terms of morbidity and mortality.

LSdeV was supported by the National Fund for Research into Crippling Diseases (Action Research for the Crippled Child).

\section{References}

${ }^{1}$ Lou HC, Lassen NA, Friis-Hansen B. Impaired autoregulation of cerebral blood flow in the distressed newborn infant. J Pediatr 1979;94:118-21.

${ }^{2}$ Pape KE, Wigglesworth JS. Haemorrhage, ischaemia and the perinatal brain. London: Spastic International Medical Publications, 1979

${ }^{3}$ Perlman J, Goodman S, Kreusser K, Volpe J. Reduction in intraventricular hemorrhage by elimination of fluctuating cerebral blood flow velocity in preterm infants with respiratory distress syndrome. $N$ Engl J Med 1985;312:1353-7.

${ }^{4}$ Fujimura M, Salisbury DM, Robinson RO, et al. Clinical events relating to intraventricular haemorrhage in the newborn. Arch Dis Child 1979;54:409-14.

5 Szymonowicz W, Yu VYH, Wilson FE. Antecedents of periventricular haemorrhage in infants weighing $1250 \mathrm{~g}$ or less at birth. Arch Dis Child 1984;59:13-7.

${ }^{6}$ De Vries LS, Dubowitz V, Lary S, et al. Predictive value of cranial ultrasound in the newborn baby: a reappraisal. Lancet 1985 ;ii: $137-40$.

Correspondence to Dr A Whitelaw, Department of Paediatrics and Neonatal Medicine, Royal Postgraduate Medical School, Hammersmith Hospital, London W12 0HS.

Received 16 March 1987 